International Journal of Child, Youth and Family Studies (2011) 2.1: 263-293

\title{
GOVERNMENT COSTS ASSOCIATED WITH DELINQUENT TRAJECTORIES
}

\author{
Wendy Craig', Lyndall Schumann"1, \\ Kelly Petrunka ${ }^{2}$, Shahriar Khan ${ }^{2}$, and Ray Peters ${ }^{2}$
}

\begin{abstract}
The objectives of this project were to: (a) identify early trajectories of delinquency for both boys and girls at ages 8 (Grade 3), 11 (Grade 6), and 14 (Grade 9) in a longitudinal sample of 842 at-risk youth from a multi-informant perspective (i.e., parents, teachers, selfreported youth ratings), and (b) estimate the costs associated with each delinquency trajectory on utilization of resources in the criminal justice system, remedial education, health care and social services, and social assistance. The results indicated six distinct trajectories of delinquency: two low groups, two desisting groups, an escalator group, and a high delinquency group. There were significantly more females than males in the two low delinquency trajectory groups, $p<.05$ for both analyses. Furthermore, both the youth from the two desisters trajectory groups (13\% of the sample) and from the two most at-risk trajectories (escalators and high delinquency, 5\% of the sample) each accounted for approximately $40 \%$ of the estimated costs to government. It is interesting to note that $80 \%$ of the estimated Criminal Justice costs were due to the high delinquency and escalators trajectory groups. Antisocial or delinquent girls cost society more money than antisocial or delinquent boys in all domains, with the exception of the Social Assistance domain. Implications for crime prevention are discussed.
\end{abstract}

Key Words: delinquency, trajectories, costs, risk, and protective factors

Acknowledgement: We would like to acknowledge the following funding agencies that have contributed to this research over the last 20 years: Public Safety Canada (2007-2010); Ontario Mental Health Foundation (2006-2008); Ontario Ministry of Children and Youth Services (2005-2006); Ontario Ministry of Health and Long Term Care (2000-2004); and Ontario Ministry of Community and Social Services (1990-2000). We are grateful to the research families, youth, and teachers who have participated in this research.

Correspondence should be addressed to Wendy Craig, Psychology Department, 62 Arch Street, Kingston, Ontario, K7L 3N6, wendy.craig@queensu.ca

${ }^{1}$ Queen’s University, Psychology Department, 62 Arch Street, Kingston, Ontario K7L3N6

${ }^{2}$ Queen’s University, Better Beginnings, Better Futures, 98 Barrie Street, Kingston, Ontario K7L3N6

Canadian Research Perspectives for Youth at Risk for Serious and Violent Offending: Implications for Crime Prevention Policies and Practices 
Delinquency is one of the most prevalent problem behaviours engaged in by Canadian youth. Statistics Canada (Savoie, 2006) indicates that over one-third of youth have been involved in some form of delinquency by the age of 14 and that childhood delinquency tends to predict violent behaviours throughout the course of a lifetime. Although delinquency covers a wide range of behaviours, many of which do not go reported to the police, about $5 \%$ of Canadian youth have been charged with federal offences (Savoie, 2006). Engaging in delinquent behaviour has been linked to negative psychological, emotional, health, social, academic, employment, and criminal outcomes (Boyd et al., 2005; Lacourse, Nagin, Tremblay, Vitaro, \& Claes, 2003; Marti, Stice, \& Springer, 2010). There are significant individual, criminal, health, social, and societal costs associated with delinquency. The high intra-personal, interpersonal, and societal costs highlight the need to increase our understanding of delinquency behaviour before it emerges. In this paper, we examine the developmental trajectories of delinquency and provide an economic analysis of the costs tied to early pathways associated with delinquent behaviours, in order to inform prevention and intervention.

The objectives of this project were to: (a) identify early trajectories of delinquency for both boys and girls at age 8 (Grade 3), age 11 (Grade 6), and age 14 (Grade 9) in a longitudinal sample of 842 at-risk youth from a multi-informant perspective (i.e., parents, teachers, self-reported youth ratings); and (b) estimate the costs associated with each delinquency trajectory on utilization of resources in the criminal justice system (i.e., arrests and court appearances), remedial education (i.e., grade repetition and use of special education services from Grades 1 to 8), health care and social services (i.e., visits to a family physician, hospital emergency room use, serious injuries, overnight stays in a hospital, and family's involvement with the Children's Aid Society), and social assistance (i.e., families' receipt of welfare and disability payments).

\section{Development of Delinquent Behaviours}

A theory of delinquency needs to explain how differences in the frequency and severity of antisocial and criminal behaviours are associated with gender and age (e.g., Moffitt, 2001). Males are much more likely to commit crimes than females. Nonetheless, most of the literature agrees that the shape of the age-related changes is roughly the same for males and females (Maldonado-Molina, Piquero, Jennings, Bird, \& Canino, 2009; Jennings, Maldonado-Molina, \& Komro, 2010). Recently, Postlethwait, Barth, and Guo (2010) presented evidence that changes in delinquent behaviour may vary by level of depression and discipline for females and by level of substance use for males.

The frequency of offending increases with age through to late adolescence, peaks around the age of 16, and then begins to decline, continuing throughout adulthood (Carrington, Matarazzo, \& de Souza, 2005; Moffitt, 2001). Furthermore, not all children participate in delinquent behaviours, but those involved at a young age are most at risk for further delinquent behaviour throughout their lives (Carrington et al., 2005; Loeber \& Farrington, 1998). Research also shows that most people who are arrested for criminal offences begin their criminal behaviour in their teenage years and desist in their 20s (Loeber \& Farrington, 1998; Moffitt, 2001). A small group of mostly male offenders exhibit prepubertal antisocial behaviour and commit a disproportionate number of serious and often violent offences as adults; among adult offenders, this latter group is the most persistent (e.g., Carrington et al., 2005; Moffitt, 2001).

Canadian Research Perspectives for Youth at Risk for Serious and Violent Offending: Implications for Crime Prevention Policies and Practices 
Although the typical age-crime curve is depicted by a single line joining the rates of crime across the age range from early adolescence through adulthood, it reveals little about the development of criminal behaviour and about the variability in youths' level of involvement in delinquent behaviour. The goal of this paper is to identify the early trajectories of delinquency to increase our understanding of the developmental pathways of those who are most at risk for persisting in their offending patterns.

Recent methodological advances have allowed for a new statistical approach (PROC TRAJ ${ }^{1}$ ) to understanding the individual developmental patterns of delinquency. Previous studies categorizing children as delinquent have employed predetermined cut-off points in defining delinquency group membership. While these classifications may be theoretically reasonable, they do not necessarily exist naturally, and may be based on potentially misleading categorizations. Advancements in methodology for examining individuals' developmental trajectories provide researchers with the ability to transcend the use of these categorization procedures for identifying individual patterns of delinquency. Another advantage of this technique is that in contrast to hierarchical and latent growth curve modelling, it makes no assumptions regarding a continuous distribution of trajectories and therefore allows for the identification of distinct mixtures of trajectories within the population (Nagin, 1999). As well, instead of assuming heterogeneity among different trajectories, this method identifies the existing differences among groups. In addition, it is well suited for censored normal distributions in which a small, yet significant proportion of the population is affected (e.g., if $10 \%$ of children are engaged in serious, persistent delinquent activity). Finally, it treats missing data as random, thereby making full use of the data and reducing the need to over-sample for attrition.

Several studies have used trajectory analysis to distinguish individual patterns of delinquent behaviour from childhood to adolescence (e.g., Hoeve et al., 2008; Jennings et al., 2010; Schonberg \& Shaw, 2007; Wiesner \& Windle, 2006). A review of these studies highlights several important themes. First, on average, between three and six groups tend to be identified by the trajectory methodology, slightly more with self-reports than official records. Although there was a range in the number of trajectories found in each of these studies, there are three consistent trajectories identified (although differentially labelled). These trajectories include a low delinquency group (representing the majority of individuals who rarely engage in delinquent behaviour), a high delinquency group (representing a small minority of individuals who start high on delinquent behaviour and increase over time), and a desisting delinquency group (representing a minority of individuals who start with a fairly high level of delinquency but this behaviour decreases with time). In studies where more than three trajectories have been found, the three consistent groups are usually subdivided into other groups. For example, Lacourse et al. (2002) found six trajectories that included the three above as well as the low rising, low decline, and medium decline. Schonberg and Shaw (2007) identified four trajectories that included a moderate level that stays relatively consistent but engages in more delinquent activities than the abstaining group. Jennings et al. (2010) looked at seven different trajectory categories, and categorized them generally as increasing, stable, or desisting. The second important consistency across studies is that by the end of adolescence, most trajectory groups are on

1 PROC TRAJ is a statistical program that is designed to analyze data using a semi-parametric group-based trajectory approach (Jones, Nagin, \& Roeder, 2001; Nagin, 1999, 2005)

Canadian Research Perspectives for Youth at Risk for Serious and Violent Offending: Implications for Crime Prevention Policies and Practices 
the decline with respect to delinquent behaviour ${ }^{2}$. Third, across studies, there are more groups than proposed originally by Moffitt (2001).

There are, however, key methodological differences in these studies that may account for some of the differences in results. First, while all the studies included self-report measures, some also included court records (Hoeve et al., 2008) and teachers' and parents' ratings (Lacourse et al., 2002). Second, the studies varied with the geographical region. For example, some studies have participants from urban United States (Hoeve et al., 2008; Jennings et al., 2010) or urban French-speaking Canadians (Lacourse et al., 2002). Third, the studies varied with respect to the age of participants and have primarily focused on older students. Fourth, with the exception of Jennings et al. (2010) and Wiesner and Windle (2006), all of the studies only included boys. Although fewer girls than boys engage in high levels of problem behaviours, those girls who do start early and persist in antisocial behaviours experience mental health problems at levels equal to their antisocial male counterparts (Jennings et al., 2010; Odgers et al., 2008). Thus, there are limited data available on the trajectories of delinquency in girls. Fifth, some of the studies conceptualized delinquency broadly and examined externalizing behaviours (i.e., conduct problems, physical aggression, oppositional behaviour, hyperactivity) as opposed to delinquency (defined by violations of the Criminal Code). Sixth, studies varied with respect to the number of assessments and the timing of assessments used to derive the trajectories. Thus, the operationalizing of delinquency and the study design may in part influence the differences in the shape and the number of the trajectories. Despite these methodological differences across studies, the consistent finding of at least three similar trajectories on different populations and cultures provides strong test re-test reliability to these three trajectories. The current paper furthers the research by using multiple informants in identifying the economic cost associated with each different type of delinquent trajectory, starting from an early age.

\section{Estimated Costs Associated with Delinquency}

Despite the well-documented individual, psychological, physical and mental health, social, and criminal outcomes of engaging in delinquent behaviours, there are limited data available in Canada on the costs associated with it. There is also a paucity of research on the costs of delinquency beyond costs savings of early prevention programs on future delinquency, and the costs to the criminal justice system. Antisocial youth tend to be multiple offenders and Cohen (1998) found that the average delinquent commits 68 to 80 crimes over their delinquency time period and costs society between $\$ 1.3$ million and \$1.5 million. Cowell et al.’s (2010) study of teenaged arrestees found evidence that intervention programs targeting youth after their first arrest are slow to reduce juvenile justice costs for these individuals. Early intervention programs, on the other hand, do have the potential to reduce the long-term costs of delinquency. Cohen and Piquero (2009) estimated that a beneficial prevention program of diverting a 14-year-old high-risk juvenile from a life of crime could save from \$2.6 million to \$5.3 million (U.S. dollars).

Few studies of early childhood prevention programs for children in the U.S. and only one in Canada have included an economic analysis (e.g., Karoly, Kilburn, \& Cannon, 2005; Mrazek \& Brown, 2002; Peters et al., 2010; Waddell, Hua, Garland, Peters, \& McEwan, 2007). Four notable

\footnotetext{
2 With the exception of Jennings et al. (2010), who found that virtually all of the males who were assigned to any of the delinquent trajectories were either maintaining their rates of offending or increasing their offending by the end of the 7th and 8th grade school year. This result may be explained by the fact that the participants were not followed to the end of adolescence as was the case in the other studies.
}

Canadian Research Perspectives for Youth at Risk for Serious and Violent Offending: Implications for Crime Prevention Policies and Practices 
exceptions in the U.S. are the Elmira Prenatal/Early Infancy Project (PEIP; Karoly et al., 1998); the Carolina Abecedarian Project (Barnett \& Masse, 2007; Masse \& Barnett, 2002); the Chicago ChildParent Centers program (CPC; Reynolds, Temple, Robertson, \& Mann, 2002); and the High/Scope Perry Preschool Project (PPP; Barnett, 1996; Nores, Belfield, Barnett, \& Schweinhart, 2005). The Canadian study is on Better Beginnings, Better Futures (BBBF; Peters et al., 2010). All these early childhood intervention studies have reported economic analyses based on follow-up data for children, and in some cases their parents, to the child's age of 15 (BBBF and PEIP), 21 (Abecedarian and $\mathrm{CPC}$ ), and 40 (PPP). Economic analyses results from these studies provide the rationale to policy-makers for investing in early childhood interventions.

For most economic analyses of early childhood education programs, economic benefits are typically divided into three categories: benefits to program participants (e.g., increased income from improved education); benefits to non-program participants (e.g., reduced costs to crime victims); and benefits to government/taxpayers (e.g., decreased remedial education costs, decreased costs to the justice system). The costing perspective of the Canadian BBBF economic analysis was the government/taxpayers; Karoly et al. (1998) refer to this analysis as cost-savings analysis to differentiate it from the more traditional cost-benefit analysis. In this paper, we will examine the social, health, educational, and juvenile justice costs for each of our trajectories based on data from the BBBF study. This is the first study in Canada to include girls in this type of analysis.

Of particular note, Cohen, Piquero, and Jennings (2010) have recently looked at the costs of adult criminal offending of unique trajectories disaggregated across gender and ethnicity. They found that chronic offenders who did not desist in their late adolescence, went on to commit more serious crimes and ultimately cost far more than low-frequency chronic offenders. The present study aims to extend this methodology to a Canadian sample using parent, teacher, and youth informants, and, for a more comprehensive cost estimate, to include more cost measures than solely the cost directly accrued from an offence.

In summary, most studies of juvenile delinquency over the past two decades have focused on older, serious, and violent juvenile offenders. Younger delinquents have been ignored partly because their number is relatively small and their threat is not as immediate. However, whereas the number of very young offenders is small compared with older juveniles, child delinquents present unique challenges that need to be addressed. Intervening before minor offences become more serious and before the occasional offender becomes a chronic offender is important, and more effective. Furthermore, past studies have focused on the cost-benefit analysis of individual prevention programs, but not the comprehensive (including social, health, and educational) cost-savings analysis of particular delinquent trajectories, using multi-informant data. Understanding the trajectories and costs of delinquency at a young age is paramount to developing efficient strategies that target individuals at young ages to improve the outcomes of those in high-risk groups.

\section{Method}

\section{Participants}

In the BBBF sample, the longitudinal research cohort was comprised of a focal cohort and a following cohort. Children in the focal cohort $(n=721)$ were born in 1989 and were recruited to the 
longitudinal study between Junior Kindergarten (JK) and Grade 3, mostly through the school system. Children in the following cohort $(n=238)$ were born in 1990, and were recruited to the longitudinal study when they were in Grade 3. For this study, there were 842 participants (396 girls and 446 boys), representing $88 \%$ of the original sample. These participants represent the longitudinal followup of the BBBF study and had data at ages 8 (Grade 3), 11 (Grade 6), and 14 (Grade 9).

Attrition was mainly due to two factors: families relocated and the researchers were unable to contact them or families declined to be interviewed. As a test for attrition bias, we employed logistic regression to examine socio-demographic differences in children and families who dropped out of the research cohort between Grades 3 and 6 and between Grades 6 and 9, and families who completed all years of data collection. These analyses indicated no significant differences in sociodemographic variables between the retained and lost cases.

Approximately 30\% of the households were headed by single parents, 34\% of parents did not complete high school, 59\% of families were living below the Statistics Canada Low Income Cut-off line, and 19\% were living in public housing. There were no significant gender differences on any of the demographic variables.

\section{Measures}

Delinquency. Child delinquency measures were created using items from the National Longitudinal Survey of Children and Youth (NLSCY; Statistics Canada, 1995). Three different measures were created, one for parents, one for teachers, and one for the youth themselves. Ratings in Grade 3 were provided by teachers only, while ratings in Grade 6 were provided by parents, teachers, and youth, and ratings in Grade 9 by parents and youth. Items for the parent and teacher versions and the Grade 6 youth version were rated on a three-point scale: $0=$ never or not true, $1=$ sometimes or somewhat true, and 2 = often or very true (e.g., "vandalizes”, "steals”, "destroys things", and "tells lies or cheats”). At Grade 9, the youth indicated whether or not in the past 12 months, they were part of a gang $(0=$ no, $1=$ yes $)$ and the remaining nine items were rated $0=$ never, 1 = once or twice, 2 = three or four times, or 3 = five or more times (e.g., "stayed out all night without permission”, “stolen something”, “sold drugs”, and “intentionally destroyed/damaged things”). Using principal component factor analyses, delinquency items from teachers, parents, and youth were combined separately at each of the three grades to create Grades 3, 6, and 9 delinquency scales: The Grade 3 delinquency scale was created by combining three teacher-rated items; the Grade 6 measure had 13 items (6 parents, 5 teachers, and 2 youth); and the Grade 9 measure of delinquency included 16 items (6 parents and 10 youth). All three scales had high inter rater and test re-test reliabilities.

Estimated Costs of Government Resources Associated with Delinquency. We identified 12 measures in our data set that could be monetized to reflect children's and parents' utilization of government resources in health care and social services, remedial education, the criminal justice system, and social assistance (see Table 1 for summary). These measures were collected from children and their parents beginning when the children were in Junior Kindergarten (JK) up to and including Grade 9 (more specific details on how each of the 12 outcomes was monetized can be requested from the authors). 
Table 1. Estimated Costs of Government Resources

\begin{tabular}{|c|c|}
\hline GOVERNMENT RESOURCE & ESTIMATED COSTS IN CANADIAN DOLLARS ${ }^{A}$ \\
\hline \multicolumn{2}{|l|}{ Health Care and Social Services } \\
\hline Visits to a family physician & $\begin{array}{l}\text { \$29.44 per visit in Ontario based on } 2001 \\
\text { dollar figures (Browne, Gafni, \& Roberts, } \\
\text { 2002) }\end{array}$ \\
\hline Hospital emergency room use & $\begin{array}{l}\text { \$195.76 per visit in Ontario based on } 2001 \\
\text { dollar figures (Browne et al., 2002) }\end{array}$ \\
\hline Number of serious injuries & $\begin{array}{l}\text { The average cost of an unintentional injury in } \\
\text { Canada was } \$ 4,000 \text { in } 1996 \text {. (Angus et al., } \\
\text { 1998) }\end{array}$ \\
\hline Number of overnight stays in hospital & $\begin{array}{l}\$ 816.35 \text { per overnight stay in a hospital in } \\
\text { Ontario based on } 2001 \text { dollar figures. } \\
\text { (Browne et al., 2002) }\end{array}$ \\
\hline Visits with a nurse practitioner & $\begin{array}{l}\$ 19 \text { per visit in Ontario based on } 2001 \text { dollar } \\
\text { figures (Browne et al., 2002) }\end{array}$ \\
\hline $\begin{array}{l}\text { Family involvement with Children's Aid } \\
\text { Society }\end{array}$ & $\begin{array}{l}\$ 60 \text { per visit in Ontario based on } 2001 \text { dollar } \\
\text { figures (Browne et al., 2002) }\end{array}$ \\
\hline \multicolumn{2}{|l|}{ Remedial Education } \\
\hline Grade repetition & $\begin{array}{l}\$ 6,151 \text { per year in Ontario based on } 2002 / 03 \\
\text { school year dollar figures. }\end{array}$ \\
\hline Use of special education services & $\begin{array}{l}\$ 6,794 \text { average cost per child receiving } \\
\text { special education services in Ontario based } \\
\text { on } 2001 / 02 \text { school year dollar figures. }\end{array}$ \\
\hline \multicolumn{2}{|l|}{ Criminal Justice System } \\
\hline Arrests & $\begin{array}{l}\$ 500 \text { Canadian national average cost per } \\
\text { police investigation in } 1998 \text { (Hepworth, 2000) }\end{array}$ \\
\hline Court appearances & $\begin{array}{l}\$ 1,250 \text { Canadian national average court } \\
\text { costs (Hepworth, 2000) }\end{array}$ \\
\hline Social Assistance Programs & \\
\hline
\end{tabular}


International Journal of Child, Youth and Family Studies (2011) 2.1: 263-293

\begin{tabular}{|l|l|}
\hline Social Welfare Assistance & $\begin{array}{l}\text { \$842 per month in Ontario based on } 2003 \\
\text { estimated minimum value of basic social } \\
\text { assistance for a single parent with one } \\
\text { dependent child (National Council on } \\
\text { Welfare, 2004) }\end{array}$ \\
\hline Ontario Disability Support Program & $\begin{array}{l}\text { \$829 (single parent with one child) and \$940 } \\
\text { (two parents with one child) per month in } \\
\text { Ontario based on 2003 estimated minimum } \\
\text { payments (Ontario Ministry of Community } \\
\text { and Social Services, 2003) }\end{array}$ \\
\hline
\end{tabular}

${ }^{\text {a }}$ A 3\% discount rate was applied for all estimated cost data. 


\section{Data Analysis}

To identify the trajectories of delinquency, we used the semi-parametric group-based trajectory approach (Jones et al., 2001; Nagin, 1999, 2005). In this modelling, the dependent variable was the total standardized delinquency scale score at Grades 3, 6, and 9. The censored normal distribution was used to model the trajectories to account for the censoring at the lower and upper bounds of the delinquency scale. A polynomial relationship was used to link age to delinquency behaviour. We compared models with different numbers of groups using a Bayesian information criterion (BIC) (Kass \& Raftery, 1995). A large BIC value corresponds to a good model with a large log-likelihood value and not too many parameters. We tested competing models of 2, 3, 4, 5, and 6 groups of delinquency to determine the "best" model based on BIC criterion; we found that the BIC values for two-, three-, four-, five-, and six-group models were, respectively, -886.8, -881.2, -894.4, -851.8, and -838.2. Application of the maximum BIC for model selection indicated that the six-group solution was the "best" model for the combined sample of girls and boys.

To estimate costs associated with each trajectory of delinquency, we estimated an average cost/child/trajectory for each of the 12 monetizable government resources described in Table 1. For each child, we estimated the costs of utilizing the government resource by multiplying the unit cost available from a secondary source (e.g., \$29.44 for an appointment with a family physician) by the occurrence of the event. All dollar figures that we report were discounted at a rate of $3 \%$. This discount rate falls within the range of rates commonly used and recommended in public policy analysis (e.g., Karoly et al., 1998; Karoly et al., 2005; Reynolds et al., 2002). All missing values, including the values of the missing grades (such as Grades 4, 5, 7, and 8 when no data collection took place), were interpolated, given that there were at least $60 \%$ data points present. Each gradespecific cost figure was then combined and reclassified into three major groups - JK to Grade 3 (ages 4 to 8), Grade 4 to Grade 6 (ages 9 to 11), and Grade 7 to Grade 9 (ages 12 to 14) - and presented by delinquency group trajectories and child's gender. We used the following equation to estimate the average cost for each of the 12 measures of utilization of government resources for each grade. The cost values are based on the value $(v)$ of each outcome as outlined in Table 1 (e.g., \$29.44 for a visit to a family physician), multiplied by frequency of occurrence $(o)$ of that outcome for each child for that year.

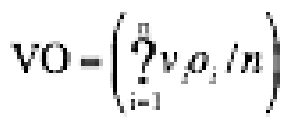

where, $\mathrm{VO}=$ Average cost for an outcome measure in a grade;

$$
\begin{aligned}
& i=\text { number of children }(1, \ldots, n) ; \\
& n=\text { sample size; } \\
& v=\text { value of outcomes }(\$) ; \\
& o=\text { occurrences of the outcome. }
\end{aligned}
$$




\section{Results}

\section{Trajectories of Delinquency}

According to the statistical tests, the six-group solution was the "best" model for the combined sample of girls and boys. Figure 1 depicts the distinct developmental trajectories of the six-class model for delinquency. Children in two of the trajectories had very low ratings of delinquency across time; we labelled these groups the lowest delinquency group and the second lowest delinquency group. Two other trajectories showed a similar pattern of delinquency ratings that was decreasing over time. In the moderate desisters group, children had moderate levels of delinquency at Grade 3, followed by low levels of delinquency at Grades 6 and 9. In the highest desisters group, children had the highest level of reported delinquency behaviours at Grade 3, followed by a marked decrease in reported delinquency at Grades 6 and 9. The fifth trajectory group, labelled escalators, had very low levels of reported delinquency at Grade 3 and increased markedly in their reported delinquency over time. By Grade 9, children in this trajectory had the second highest delinquency scores. The final group, labelled high delinquency, started with moderate levels of reported delinquency at Grade 3, marked by the highest reported levels of delinquency at Grades 6 and 9 of any of the trajectory groups. See Figure 1.

\section{Figure 1. Delinquency Trajectories of At-Risk Youth}

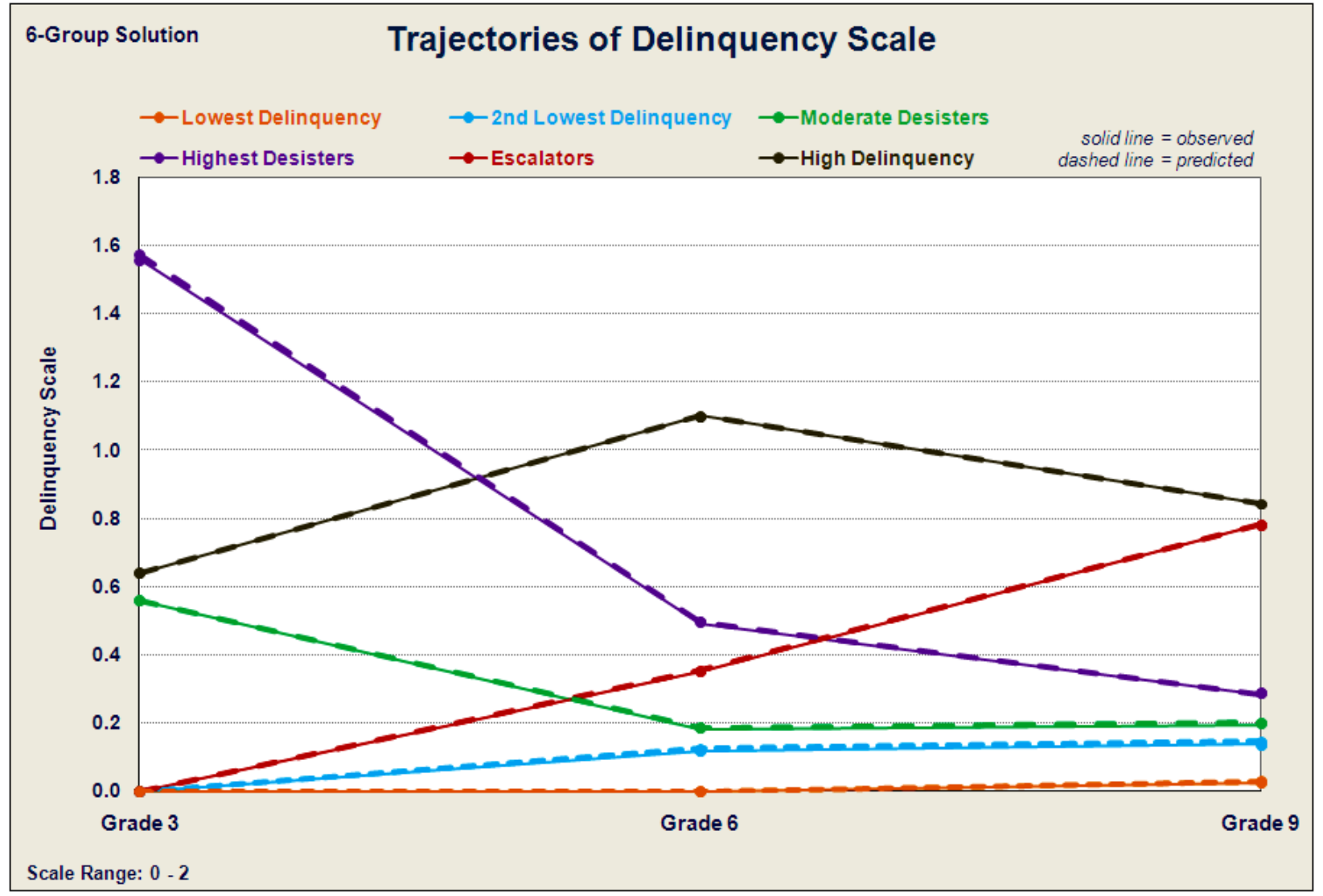

Canadian Research Perspectives for Youth at Risk for Serious and Violent Offending: Implications for Crime Prevention Policies and Practices 
Table 2 depicts the percentages of children in each of the groups. Chi-squares tested for gender differences in the group membership of each trajectory group; a significant group by gender effect was found, that is, that there was a significant difference in the proportion of males compared to the proportion of females $(p<.003)$. We then compared whether the proportion of males versus females differed for each of the six trajectory groups separately. There were significantly more females than males in the two low delinquency trajectory groups, $p<.05$ for both analyses. There were more males than females in the four remaining trajectory groups, but only the differences for the trajectory groups showing marked decreases in delinquency over time were significant (the moderate and highest desisters), $p<.05$ for both analyses.

Table 2. Percentage of Boys vs. Girls in Each Trajectory

\begin{tabular}{lcc}
\hline Trajectory Group & Males & Females \\
& $\%(\mathrm{n})$ & $\%(\mathrm{n})$ \\
\hline Lowest Delinquency* $^{\star}$ & $6.7 \%(30)$ & $10.6 \%(42)$ \\
Second Lowest Delinquency* & $70.4 \%(314)$ & $76.5 \%(303)$ \\
Moderate Desisters* & $13.5 \%(60)$ & $8.1 \%(32)$ \\
Highest Desisters* & $3.4 \%(15)$ & $1.0 \%(4)$ \\
Escalators & $4.0 \%(18)$ & $2.8 \%(11)$ \\
High Delinquency & $2.0 \%(9)$ & $1.0 \%(4)$ \\
\hline
\end{tabular}

${ }^{*} p<.05$, therefore significant sex differences. 


\section{Estimated Costs Associated with Delinquency Trajectories}

Table 3 provides a summary of the government expenditures by general domain by trajectory group. To briefly summarize the results, government expenditures were highest in the Remedial Education domain (64\% of costs), followed by Health Care and Social Services (29\%), Social Assistance (6\%), and Criminal Justice System (1\%). The two lowest delinquency trajectories (82\% of the sample) accounted for only $19.4 \%$ of the estimated government costs. In other words, approximately $80 \%$ of the estimated costs to government were from $18 \%$ of the sample. Specifically, we found that youth from the two desisters trajectory groups (13\% of the sample) accounted for $40 \%$ of the estimated costs to government; and youth from the two most at-risk trajectories (escalators and high delinquency, $5 \%$ of the sample) accounted for $40.6 \%$ of the estimated costs to government. It is interesting to note that $80 \%$ of the estimated Criminal Justice costs were due to the high delinquency and escalators trajectory groups.

We also found that antisocial or delinquent girls cost society more money than antisocial or delinquent boys in all domains, with the exception of the Social Assistance domain. Specifically, summing across all six trajectory groups from ages 4 to 14, we estimated that girls cost \$244,056 while boys cost $\$ 229,236$. In addition, we estimated that girls’ criminal justice costs were almost twice those of boys ( $\$ 4,835$ vs. $\$ 2,408)$.

Table 3: Results of Estimated Utilization of Government Resources by Trajectory Group

\begin{tabular}{|c|c|c|c|c|c|c|c|c|c|c|c|c|c|}
\hline & \multicolumn{3}{|c|}{ JK - Grade 3 (\$) } & \multicolumn{3}{|c|}{$\begin{array}{c}\text { Grade } 4 \text { - Grade } 6 \\
\text { (\$) }\end{array}$} & \multicolumn{3}{|c|}{$\begin{array}{c}\text { Grade } 7 \text { - Grade } 9 \\
\text { (\$) }\end{array}$} & \multicolumn{3}{|c|}{ All Grades (\$) } \\
\hline & & Male & Female & All & Male & Female & All & Male & Female & All & Male & Female & All \\
\hline \multicolumn{14}{|c|}{ Health Care and Social Services } \\
\hline \multirow{5}{*}{ 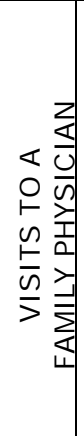 } & $\begin{array}{l}\text { 2nd lowest } \\
\text { delinquency }\end{array}$ & 110 & 103 & 107 & 58 & 54 & 56 & 52 & 48 & 50 & 220 & 205 & 212 \\
\hline & escalators & 125 & 150 & 134 & 67 & 59 & 64 & 54 & 44 & 50 & 246 & 253 & 249 \\
\hline & $\begin{array}{l}\text { high } \\
\text { delinquency }\end{array}$ & 108 & 156 & 128 & 51 & 57 & 53 & 51 & 45 & 49 & 209 & 259 & 230 \\
\hline & $\begin{array}{l}\text { moderate } \\
\text { desisters }\end{array}$ & 116 & 107 & 113 & 56 & 54 & 56 & 55 & 52 & 54 & 227 & 213 & 222 \\
\hline & $\begin{array}{c}\text { lowest } \\
\text { delinquency }\end{array}$ & 110 & 107 & 109 & 51 & 47 & 49 & 32 & 39 & 36 & 192 & 193 & 193 \\
\hline
\end{tabular}


International Journal of Child, Youth and Family Studies (2011) 2.1: 263-293

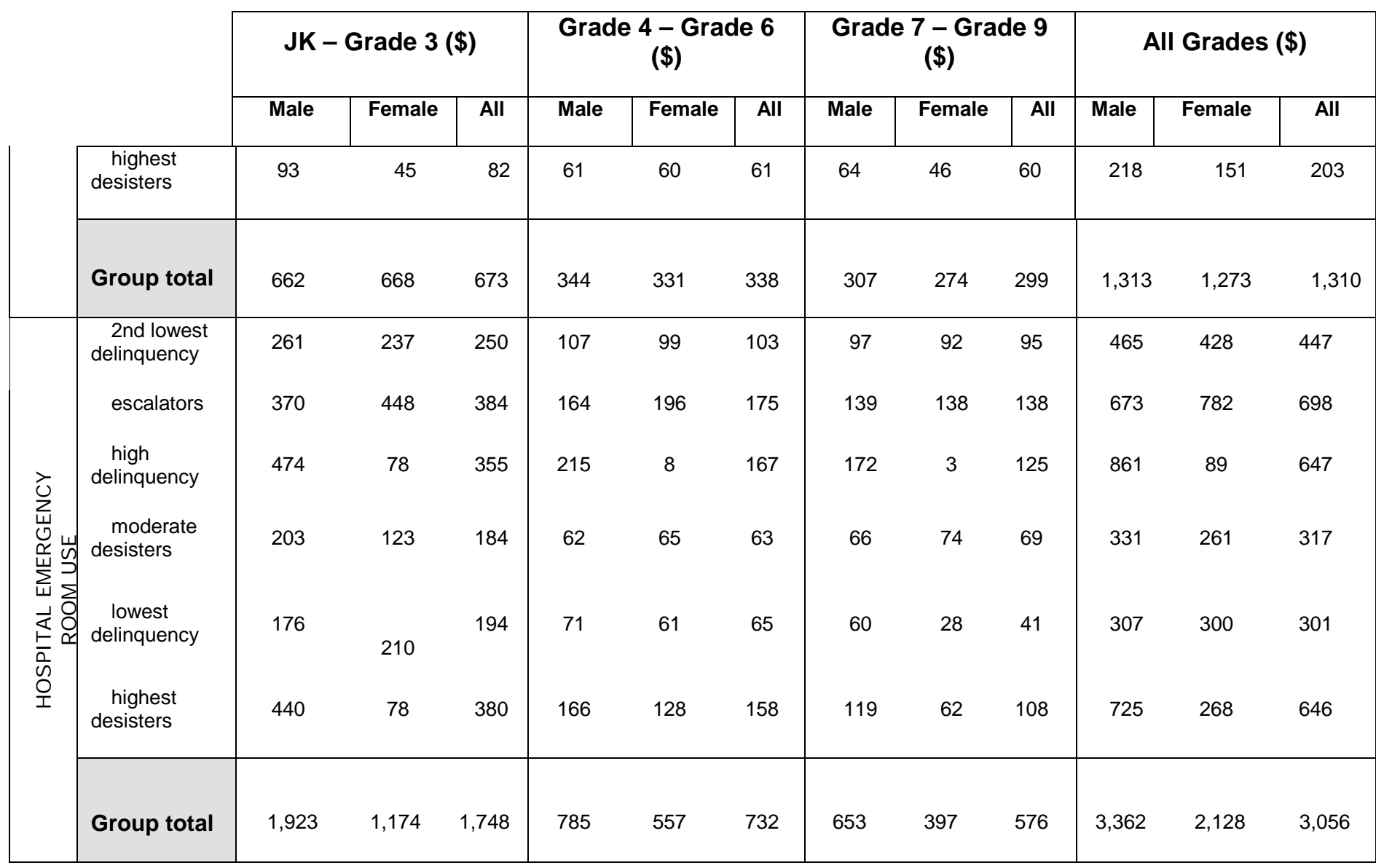


International Journal of Child, Youth and Family Studies (2011) 2.1: 263-293

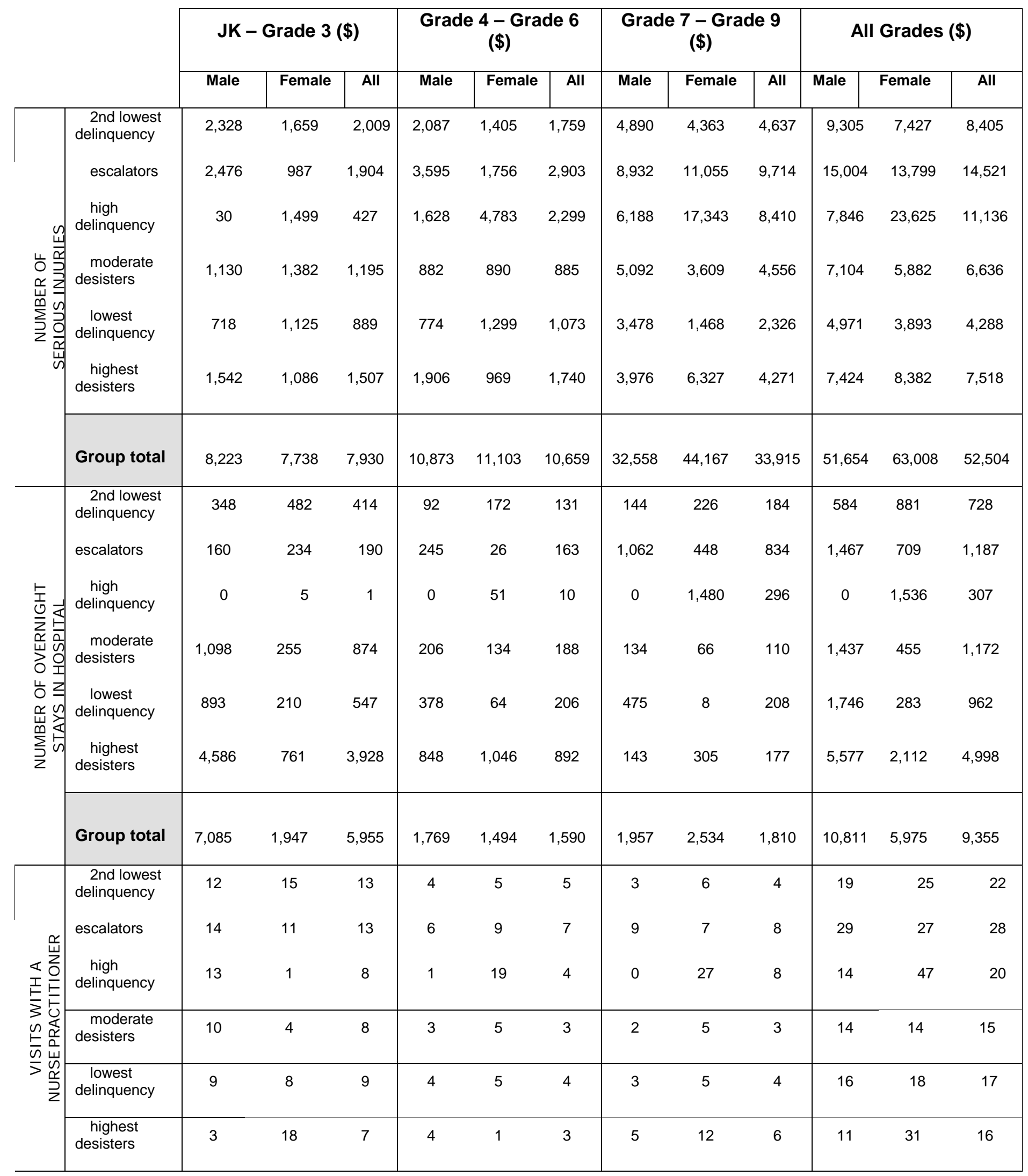

Canadian Research Perspectives for Youth at Risk for Serious and Violent Offending: Implications for Crime Prevention Policies and Practices 
International Journal of Child, Youth and Family Studies (2011) 2.1: 263-293

\begin{tabular}{|c|c|c|c|c|c|c|c|c|c|c|c|c|}
\hline & \multicolumn{3}{|c|}{ JK - Grade 3 (\$) } & \multicolumn{3}{|c|}{$\begin{array}{c}\text { Grade } 4 \text { - Grade } 6 \\
\text { (\$) }\end{array}$} & \multicolumn{3}{|c|}{$\begin{array}{c}\text { Grade } 7 \text { - Grade } 9 \\
\text { (\$) }\end{array}$} & \multicolumn{3}{|c|}{ All Grades (\$) } \\
\hline & Male & Female & All & Male & Female & All & Male & Female & All & Male & Female & All \\
\hline Group total & 61 & 56 & 57 & 21 & 43 & 27 & 21 & 63 & 34 & 103 & 162 & 118 \\
\hline
\end{tabular}


International Journal of Child, Youth and Family Studies (2011) 2.1: 263-293

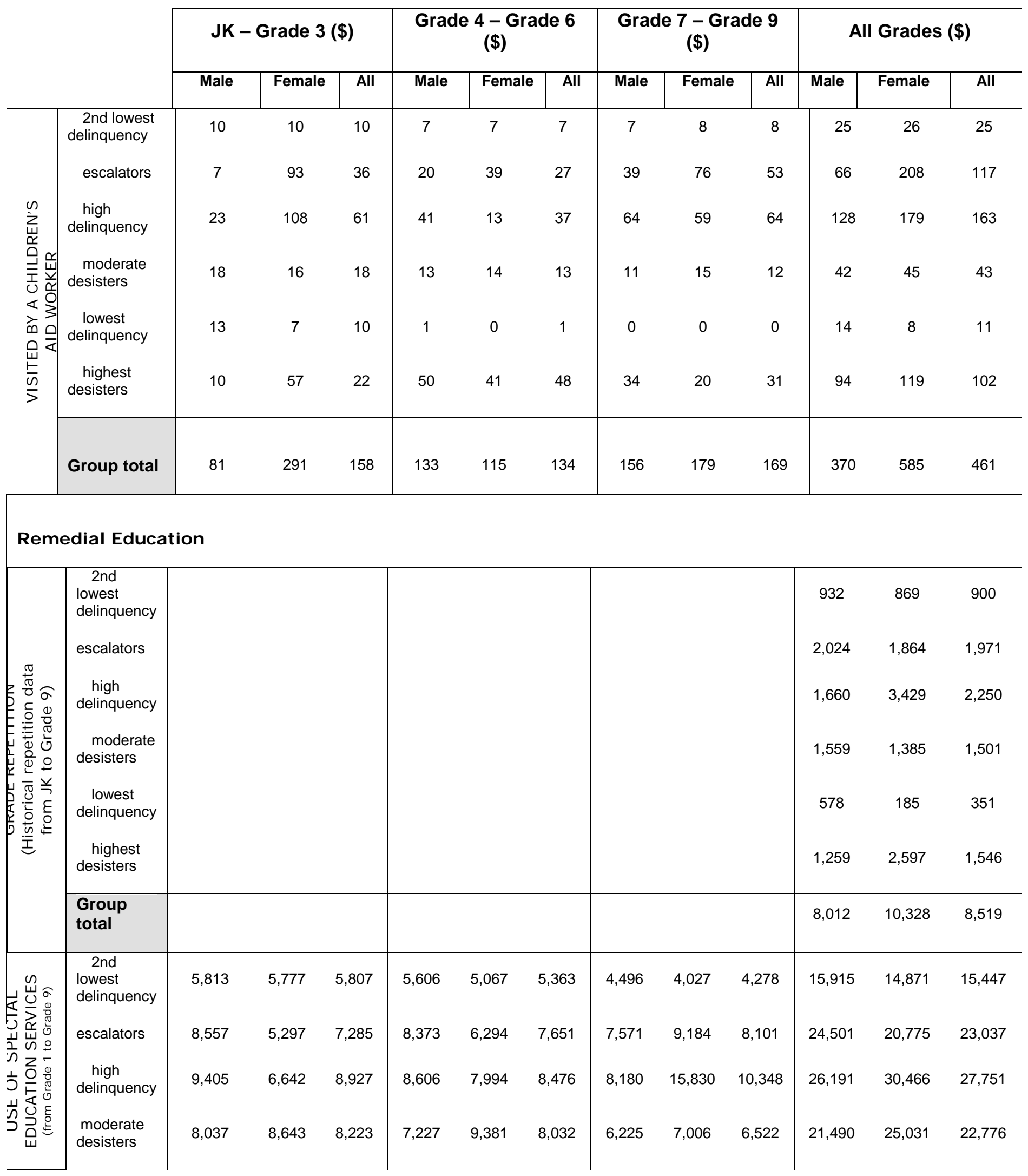

Canadian Research Perspectives for Youth at Risk for Serious and Violent Offending: Implications for Crime Prevention Policies and Practices 
International Journal of Child, Youth and Family Studies (2011) 2.1: 263-293

\begin{tabular}{|c|c|c|c|c|c|c|c|c|c|c|c|c|}
\hline & \multicolumn{3}{|c|}{ JK - Grade 3 (\$) } & \multicolumn{3}{|c|}{$\begin{array}{c}\text { Grade } 4 \text { - Grade } 6 \\
\text { (\$) }\end{array}$} & \multicolumn{3}{|c|}{$\begin{array}{c}\text { Grade } 7 \text { - Grade } 9 \\
\text { (\$) }\end{array}$} & \multicolumn{3}{|c|}{ All Grades (\$) } \\
\hline & Male & Female & All & Male & Female & All & Male & Female & All & Male & Female & All \\
\hline $\begin{array}{c}\text { lowest } \\
\text { delinquency }\end{array}$ & 5,586 & 3,647 & 4,595 & 3,920 & 2,092 & 2,898 & 3,248 & 1,090 & 2,104 & 12,754 & 6,830 & 9,596 \\
\hline $\begin{array}{l}\text { highest } \\
\text { desisters }\end{array}$ & 10,701 & 14,482 & 11,700 & 13,956 & 13,673 & 13,908 & 12,654 & 17,341 & 13,430 & 37,311 & 45,496 & 39,038 \\
\hline $\begin{array}{l}\text { Group } \\
\text { total }\end{array}$ & 48,099 & 44,489 & 46,537 & 47,688 & 44,502 & 46,327 & 42,375 & 54,477 & 44,782 & 138,162 & 143,468 & 137,646 \\
\hline
\end{tabular}


International Journal of Child, Youth and Family Studies (2011) 2.1: 263-293

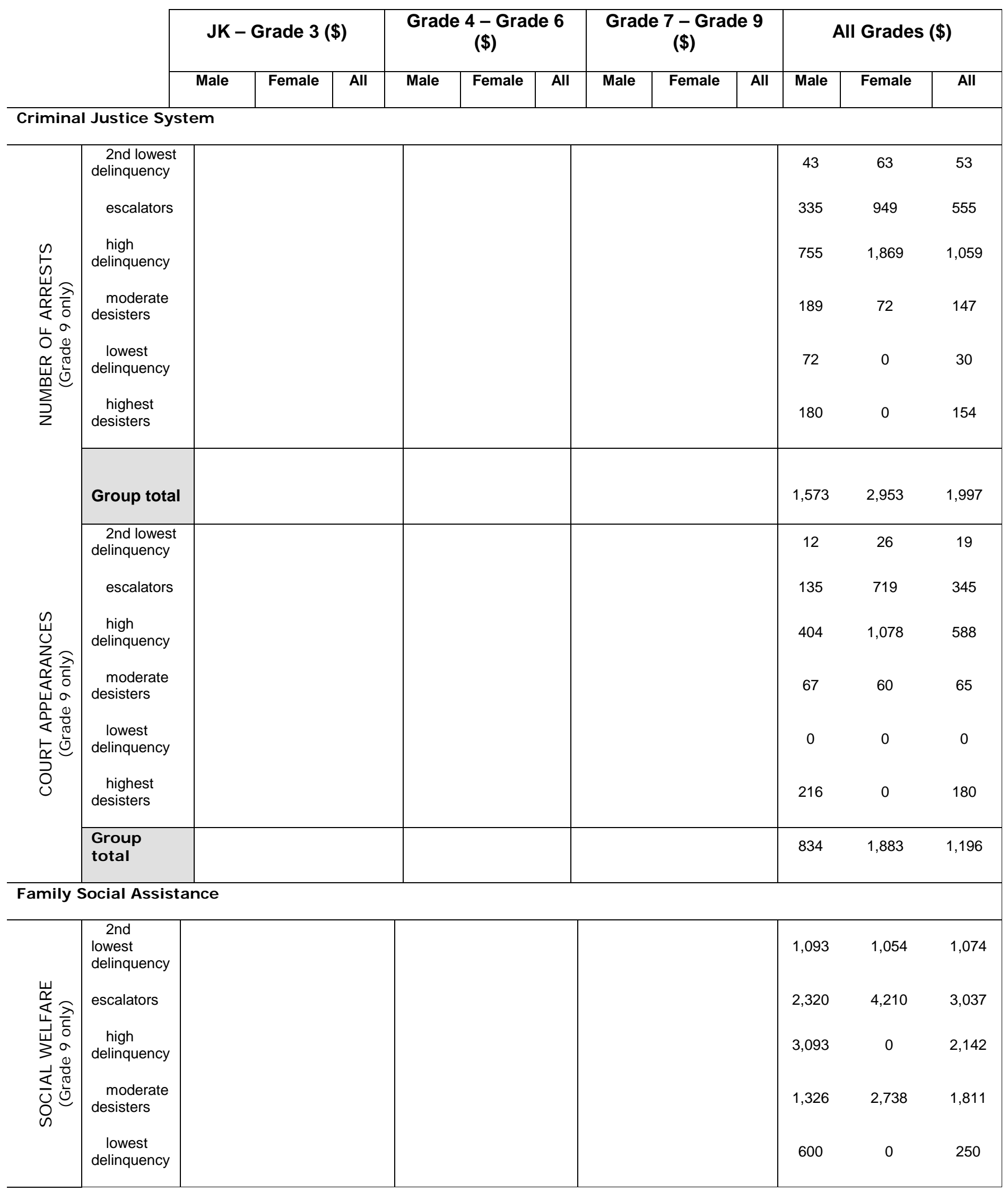

Canadian Research Perspectives for Youth at Risk for Serious and Violent Offending: Implications for Crime Prevention Policies and Practices 
International Journal of Child, Youth and Family Studies (2011) 2.1: 263-293

\begin{tabular}{|c|c|c|c|c|c|c|c|c|c|c|c|c|c|}
\hline & & \multicolumn{3}{|c|}{ JK - Grade 3 (\$) } & \multicolumn{3}{|c|}{$\begin{array}{c}\text { Grade } 4 \text { - Grade } 6 \\
\text { (\$) }\end{array}$} & \multicolumn{3}{|c|}{$\begin{array}{c}\text { Grade } 7 \text { - Grade } 9 \\
\text { (\$) }\end{array}$} & \multicolumn{3}{|c|}{ All Grades (\$) } \\
\hline & & Male & Female & All & Male & Female & All & Male & Female & All & Male & Female & All \\
\hline & $\begin{array}{r}\text { highest } \\
\text { desisters }\end{array}$ & & & & & & & & & & 2,320 & 0 & 1,856 \\
\hline & $\begin{array}{l}\text { Group } \\
\text { total }\end{array}$ & & & & & & & & & & & & \\
\hline & & & & & & & & & & & 10,752 & 8,001 & 10,169 \\
\hline \multirow{7}{*}{ 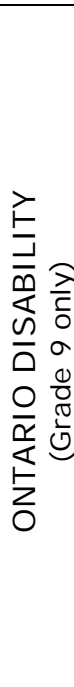 } & $\begin{array}{l}\text { 2nd } \\
\text { lowest } \\
\text { delinquency }\end{array}$ & & & & & & & & & & 709 & 660 & 685 \\
\hline & escalators & & & & & & & & & & 0 & 2,753 & 1,044 \\
\hline & $\begin{array}{l}\text { high } \\
\text { delinquency }\end{array}$ & & & & & & & & & & 0 & 0 & 0 \\
\hline & & & & & & & & & & & 904 & 577 & 792 \\
\hline & $\begin{array}{l}\text { lowest } \\
\text { delinquency }\end{array}$ & & & & & & & & & & 675 & 302 & 458 \\
\hline & $\begin{array}{l}\text { highest } \\
\text { desisters }\end{array}$ & & & & & & & & & & 0 & 0 & 0 \\
\hline & $\begin{array}{l}\text { Group } \\
\text { total }\end{array}$ & & & & & & & & & & 2,288 & 4,292 & 2,978 \\
\hline
\end{tabular}


International Journal of Child, Youth and Family Studies (2011) 2.1: 263-293

\section{Domain Total and Grand Total}

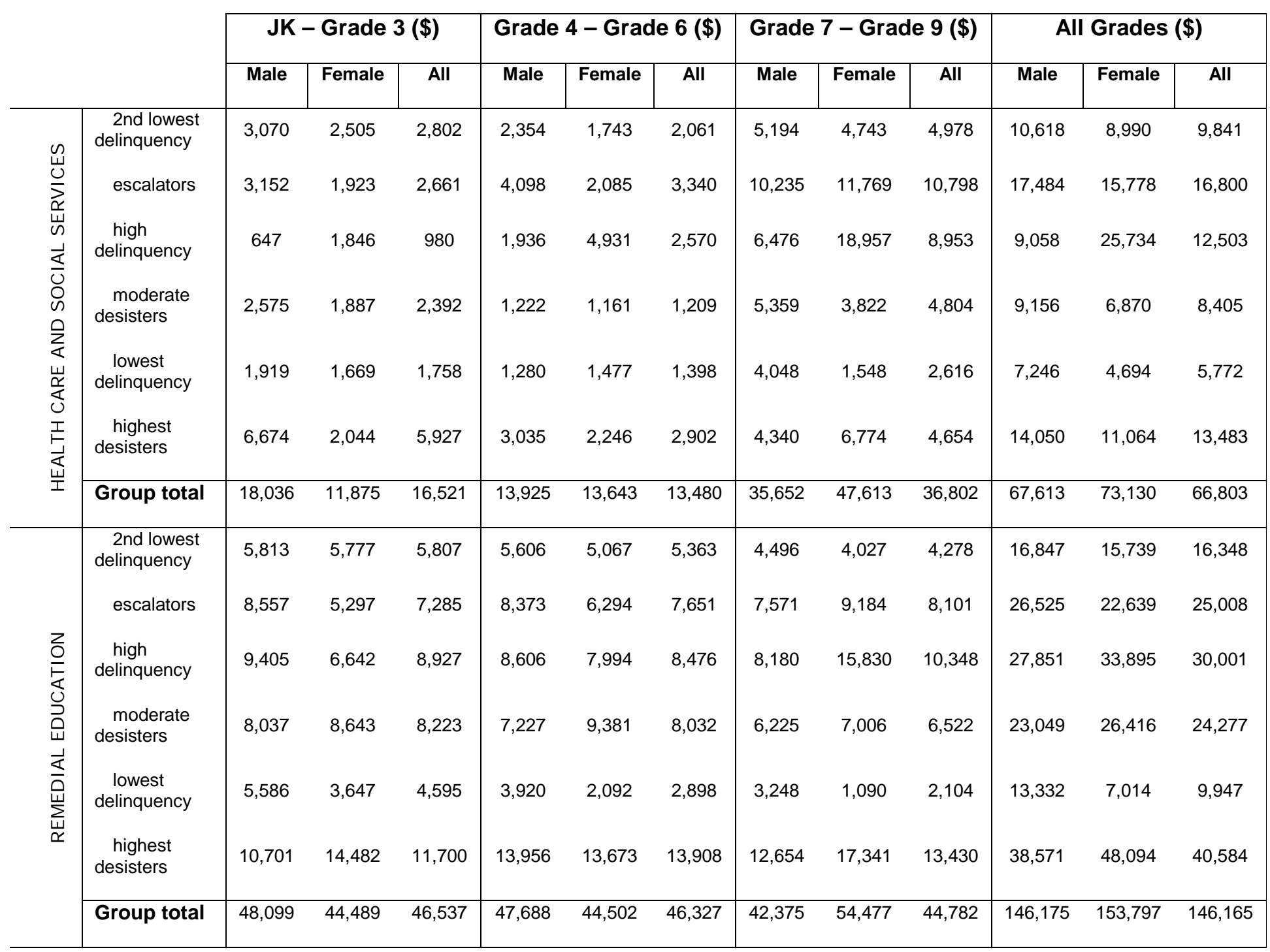


International Journal of Child, Youth and Family Studies (2011) 2.1: 263-293

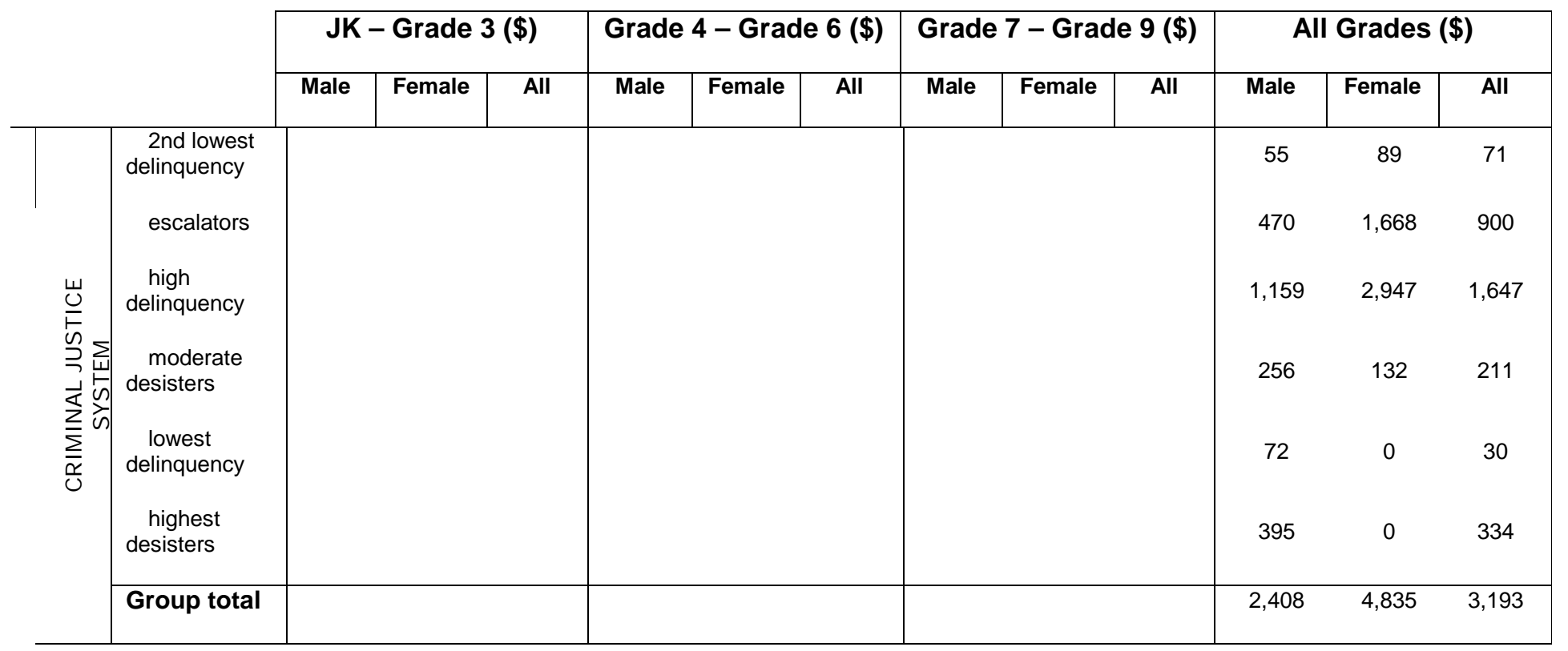


International Journal of Child, Youth and Family Studies (2011) 2.1: 263-293

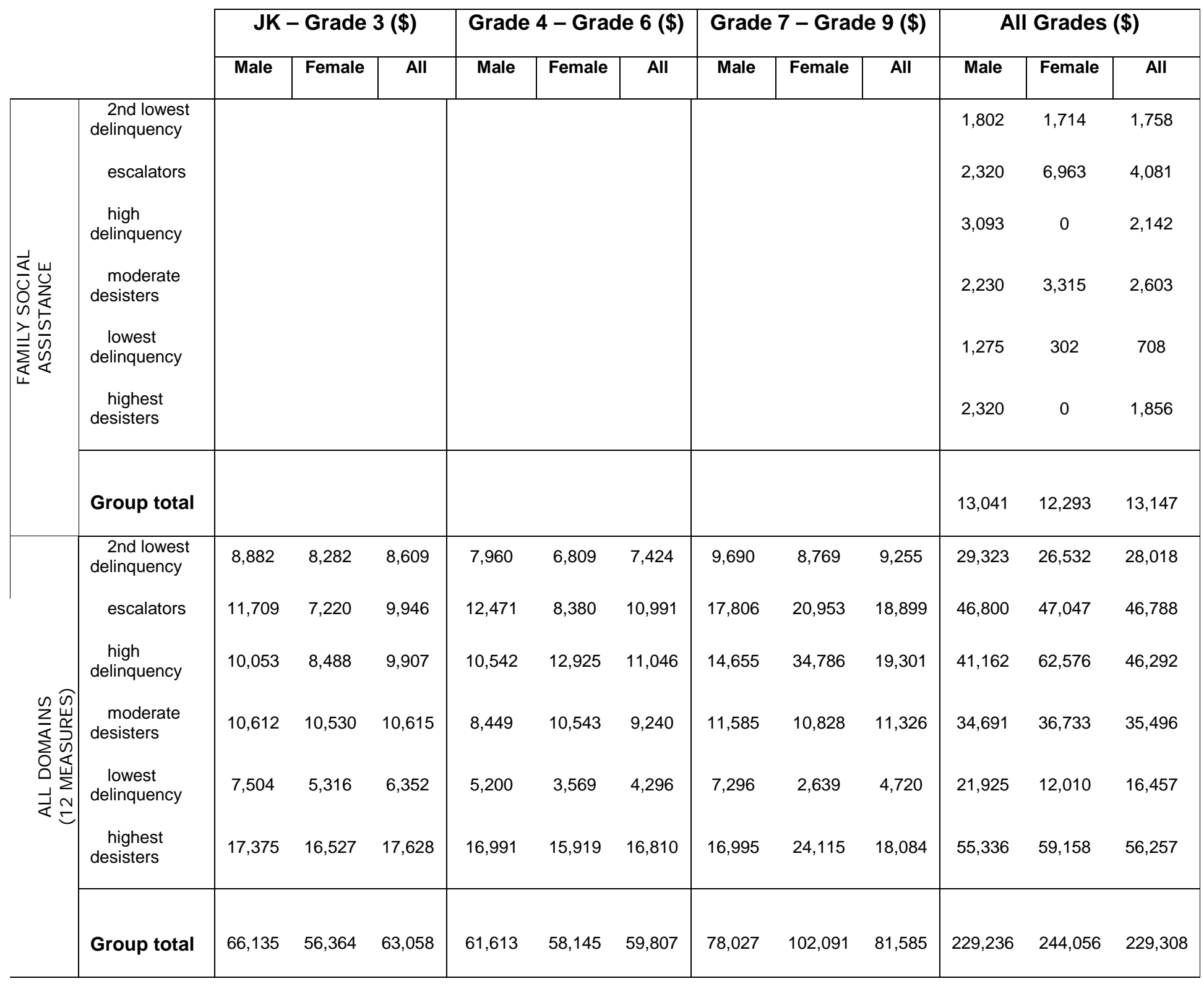

Canadian Research Perspectives for Youth at Risk for Serious and 


\section{Discussion}

Delinquency is a serious problem in our society. Over one-third of youth have been involved in some form of delinquency by the age of 14 (Farrington, 1989). Furthermore, childhood delinquency tends to predict violent behaviours throughout the course of a lifetime (Farrington, 1989). Consequently, understanding the developmental pathways that lead to delinquency is a critical issue. The current study was designed to identify the delinquency trajectories of boys and girls living in disadvantaged communities in Ontario from ages 8 to 14, and examine the estimated costs associated with each trajectory. Key messages from findings are that:

1. Children who are at risk for involvement in delinquency start early and can be potentially identified early in their development;

2. Early identification and investment may make a difference and reduce the number of children who may go on to be delinquent;

3. The costs of children at risk for delinquency begin early and are high; and

4. Early investment in education and families is important to prevent long-term criminal justice costs.

\section{Developmental Trajectories of Delinquency}

Our first objective was to examine the trajectories of delinquency in boys and girls from ages 8 (Grade 3) to 14 (Grade 9). Our results confirm the heterogeneity of the development of delinquency and are generally consistent with previous research. We found six groups of delinquency. As expected, two groups, lowest delinquency and second lowest delinquency, representing the majority of the youth $(\approx 82 \%$ of the sample) reported consistently low levels of delinquency over time. Two other trajectories (highest desisters and moderate desisters) showed a similar pattern of delinquency ratings decreasing over time, representing the desisters $(\approx 13 \%$ of the sample). Another group, the escalators $(\approx 3.5 \%$ of the sample), had very low levels of reported delinquency at Grade 3 and increased over time. Finally, the high delinquency group started with moderate levels of reported delinquency at Grade 3 and had the highest reported levels of delinquency at Grades 6 and 9 of any of the trajectory groups. The high delinquency group represented approximately $1.5 \%$ of the sample. It may be that the low percentage of youth in the high delinquency group reflects the fact that we only have data up until the youth are in Grade 9, or approximately 14 years old. Thus, many youth may just be at the beginning of engaging in delinquent acts. We hypothesize that with more longitudinal data points, the proportion of youth in the high delinquency group would increase and likely more closely resemble other research findings.

This study supported the trajectories of delinquency reported in other studies, but also identified some key differences. Similarities included that: (a) The majority of youth were involved 
in no or limited delinquent activities; (b) females were less likely than males to be involved in delinquency (i.e., there were more females in the low delinquency and second lowest delinquency trajectory groups); (c) there was a group of individuals who desisted from involvement in delinquency; and (d) there was a trajectory of consistently high engagement in delinquent behaviour. The key differences from previous literature were the number of groups that had low levels of delinquency (i.e., there were two groups - low and second lowest - that engaged in minimal delinquent behaviours). Second, the escalators and high delinquency groups had equal proportional representation of males and females. Typically, research reports that males are more likely to engage in delinquent behaviour than females and, thus, we expected to have more males than females in the high delinquency group. Third, the shape of the high delinquency trajectory group was surprising, as there was a peak in delinquency in Grade 6. We expected that the peak would not be present, and if we had extended longitudinal data, we would have expected to see it at around age 18. There are several possible interpretations to this early peak. First, no other study on delinquent trajectories has been conducted starting at such a young age. Second, the current study included girls, which no other study of delinquent trajectories has done. Third, this study was based on community sampling conducted in high-risk, low socio-economic status neighbourhoods. Lastly, it is possible that there are unique sample characteristics in the participants and the results may reflect this sampling. Nonetheless, more longitudinal research is required that begins as early as this research to validate our findings.

With our longitudinal analyses, we also examined differences in the distributions of boys and girls within the diverse trajectory groups. We found no gender differences in the distribution of boys and girls in the high delinquency group ( $2 \%$ of males and $1 \%$ of females), or in the escalators group (4\% of males and 3\% of females). This pattern is inconsistent with the general developmental trend reported by Silverthorn and Frick (1999) who found that girls tend to experience a later onset of delinquency than boys, and the general finding that boys are more likely to be involved in high delinquent behaviour than girls. The discrepancy may arise because we have used a multi-informant approach, and have taken a person-oriented approach (as opposed to a group-oriented approach), allowing us to examine heterogeneity within the development of delinquency. The small minority of at-risk girls in our sample demonstrated these problems as early as boys. Consistent with other research, we found that girls were overrepresented in the two low delinquency groups. However, we found there were significantly more males in the two desisters groups.

Trajectories increase our understanding of delinquency development and identify behavioural patterns that emerge in individuals on a specific trajectory. Once these trajectories are identified, specific factors pertaining to the individual, peers, family, and community in general can be explored to determine which factors heighten the risk of delinquency (i.e., the chronic or increasing trajectories) or act as a protective factor against the involvement in delinquency (i.e., low, noninvolved, or declining trajectories).

\section{Estimated Economic Costs Associated with Delinquency Trajectories}

The second objective of this study was to estimate the costs to government associated with each delinquency trajectory on utilization of government resources in the criminal justice system, remedial education, health care and social services, and social assistance. The majority of the 
estimated costs associated with each of the trajectories were in the educational system - $64 \%$ of the costs were for remedial education. In contrast, the percentage of the estimated costs associated with the other domains was $29 \%$ for health care and social services, $6 \%$ for social assistance, and $1 \%$ for the criminal justice system.

It was the desisters groups (highest desisters and moderate desisters) who received the most special educational services, and this likely was a positive and preventive investment. Approximately $80 \%$ of the estimated costs to government were due to the two desisters trajectory groups (highest desisters and moderate desisters) and the youth from the two most at-risk trajectories (escalators and high delinquency) who represented $18 \%$ of the sample. Specifically, we found, first, that youth from the two desisters trajectory groups (13\% of the sample) accounted for $40 \%$ of the estimated costs to government (primarily driven by education costs, a preventive response); and, second, youth from the two most at-risk trajectories (escalators and high delinquency, $5 \%$ of the sample) accounted for $40.6 \%$ of the estimated costs to government. A review of the specific estimated health care costs indicates that the escalators in particular had the highest costs associated with visiting their doctor, going to the emergency room, having serious injuries, and visiting with a nurse practitioner. These are reactionary costs (as opposed to preventive costs) in the sense that a significant event has happened. Furthermore, for girls in the high delinquency group, some costs were estimated as being much higher than for boys (e.g., the number of serious injuries, and overnight stays in hospital). Atrisk girls may be particularly vulnerable to medical problems associated with delinquency involvement compared to at-risk boys.

High-risk girls were also more costly with respect to the criminal justice system. Compared to boys, the total estimated costs at age 14 (Grade 9) for girls were almost twice that for boys $(\$ 4,835$ vs. \$2,408). The data revealed that girls in the two high-risk groups (high delinquency and escalators) were much more likely to have higher costs associated with both being arrested and appearing in court. It appears that girls, once arrested, were also much more likely to enter the criminal justice system. Admittedly, our sample of girls was small and may not be representative, but it does reflect the developmental course and costs associated with a small sample of very high-risk delinquent girls. The high-risk boy groups also had the highest estimated costs, but not as high as those of the high-risk girls. In summary, our findings suggest that girls cost the government more money than boys in all domains (except social assistance). Specifically, summing across the six trajectory groups, we estimated that, between the ages of 4 and 14, girls cost $\$ 244,056$ while boys cost $\$ 229,236$.

Additionally, $80 \%$ of the estimated criminal justice costs were due to the high delinquency and escalators groups. Even though the estimated criminal justice system costs to government were relatively low as of Grade 9 (only 1\% of the overall costs), these two groups may just be getting started and the costs associated with these groups can only increase. Interestingly, the high delinquency and escalators groups accounted for $46 \%$ of the reactive costs (such as criminal justice system, health care, and social services) compared to 32\% for the two desisters groups and $22 \%$ for the two low delinquency groups; for the preventive costs (e.g., remedial education), the high delinquency and escalator groups accounted for $38 \%$ of the costs compared to $44 \%$ for the two desisters groups and $18 \%$ for the two low delinquency groups. The implication is that investing early in prevention costs such as remedial education may provide at-risk children and their families the opportunity to have more positive developmental outcomes and desist from delinquency involvement. As a consequence, investing in prevention can save the government money in the long 
run. The most at-risk groups did not receive sufficient early support and consequently the costs associated with them were reactive and costly.

\section{Limitations}

There are many strengths to the current research: The BBBF research sample comprised disadvantaged and at-risk communities; the communities were diverse (francophone, Aboriginal, recent immigrants, and multicultural); the sample had both boys and girls; and the data allowed for economic analyses to be conducted. This is the first on a Canadian sample. However, some of the trajectories had a small sample size and hence the results may not be generalizable. For example, in the high delinquency group, the costs of delinquent behaviour in girls were high relative to boys. It may be that this is an atypical group that had many arrests, or in fact, it may be representative of an extreme group of girls that to date have been neglected by research.

There are early indicators to the developmental pathways for delinquency. This research suggests that delinquency involvement does not just emerge, but develops over time, and without intervention, the costs associated with these problems accumulate and are serious and significant as early as Grade 9. Investment in prevention, such as educational support, can reduce delinquency involvement. The most at-risk groups for delinquency involvement (e.g., escalators and high delinquency) accounted for the majority of reactive costs (e.g., criminal justice) and not the preventive costs (e.g., remedial education). Furthermore, although more research is needed to understand the developmental delinquency trajectories of girls, they appear to require more support than do boys. Although our sample of high-risk girls was limited, there are some preliminary indications from this research that they were costly and may be experiencing emotional problems, criminal activity, and court system involvement. The costs associated with their problems may be higher than for boys because they appear not only in the criminal justice system, but also in the health care system. Traditionally, we have estimated only the criminal justice costs. It may be that this venue does not reflect the full range of costs associated with female delinquency.

This research indicates that pathways to delinquency begin early. It is well known that for the early onset of offending, youth tend to persist and desist at a later stage, and as such impose a greater social and criminal justice costs on society (Tremblay, Van Aken, \& Koops, 2009). To address crime and antisocial behaviour, Welsh (2007) has suggested that the "most hopeful" methods (derived from research in the United States and Canada) are those designed to counter "specific risk factors", such as home visiting by health professionals, pre-school programs to stimulate thinking and reasoning skills in young children, parenting education programs, cognitive and social skills training to teach children to consider the consequences of their behaviour, and teacher training and anti-bullying initiatives in schools. Thus, crime prevention needs to occur early in development and be ongoing. 
Although we have made a great deal of progress in understanding individual differences in antisocial behaviour and linking these to interventions, much work remains to be done. Research that continues to monitor the development of these trajectories could be informative as youth transition into early adulthood. The mental and physical health and other needs of children at risk for delinquency involvement should not be ignored. Their behaviours greatly affect families and communities and are costly. An examination of the youth who desist from delinquency provides strong support for the value of investing early in children to prevent negative long-term outcomes. Even modestly successful prevention and intervention investments, such as in education, yielded significant benefits, including decreasing future costs associated with delinquency, improving the well-being and safety of families, children, and youth in a community, and reducing crime and delinquency. 


\section{References}

Barnett, W. S. (1996). Lives in the balance: Age-27 benefit-cost analysis of the High/Scope Perry Preschool Program (Monographs of the High/Scope Educational Research Foundation, 11). Ypsilanti, MI: High/Scope Press.

Barnett, W. S., \& Masse, L. N. (2007). Comparative benefit-cost analysis of the Abecedarian program and its policy implications. Economics of Education Review, 26, 113-125.

Boyd, J. W., Barnett, W. S., Bodrova, E., Leong, D. J., Gomby, D., Robin, K. B., et al. (2005). Promoting children's social and emotional development through preschool. New Brunswick, NJ: National Institute for Early Education Research.

Carrington, P. J., Matarazzo, A., \& deSouza, P. (2005). Court careers of a Canadian birth cohort. Crime and Justice Research Paper Series. Statistics Canada Catalogue no. 85-561-MIE, no. 006. Ottawa: Statistics Canada.

Cohen, M. A. (1998). The monetary value of saving a high risk youth. Journal of Quantitative Criminology, 14(1), 5-33.

Cohen, M. A., \& Piquero, A. R. (2009). New evidence on the monetary value of saving a high risk youth. Journal of Quantitative Criminology, 25(1), 25-49.

Cohen, M., Piquero, A., \& Jennings, W. (2010). Studying the costs of crime across offender trajectories. Criminology \& Public Policy, 9(2), 279-305.

Cowell, A., Lattimore, P,, \& Krebs, C. (2010). A cost-benefit study of a breaking the cycle program for juveniles. Journal of Research in Crime \& Delinquency, 47(2), 241-262.

Farrington, D. P. (1989). Early predictors of adolescent aggression and adult violence. Violence and Victims, 4(2), 79-100.

Hoeve, M., Blokland, A., Dubas, J. S., Loeber, R., Gerris, J., \& Van Der Laan, P. H. (2008). Trajectories of delinquency and parenting styles. Journal of Abnormal Child Psychology, 36(2), 223-235.

Jennings, W., Maldonado-Molina, M., \& Kormo, K., (2010). Sex similarities/differences in trajectories of delinquency among urban Chicago youth: The role of delinquent peers. American Journal of Criminal Justice, 35(1-2), 56-75.

Jones, B., Nagin, D. S., \& Roeder, K. (2001). A SAS procedure based on mixture models for estimating developmental trajectories. Sociological Methods and Research, 29(3), 374-393.

Canadian Research Perspectives for Youth at Risk for Serious and

Violent Offending: Implications for Crime Prevention Policies and Practices 
International Journal of Child, Youth and Family Studies (2011) 2.1: 263-293

Karoly, L., Greenwood, P., Everingham, S., Houbé, J., Kilburn, M., Rydell, C., et al. (1998). Investing in our children: What we know and don't know about the costs and benefits of early childhood interventions. Santa Monica, CA: RAND Corporation.

Karoly, L. A., Kilburn, M. R., \& Cannon, J. S. (2005). Early childhood interventions: Proven results, future promises. Santa Monica, CA: RAND Corporation.

Kass, R. E., \& Raftery, A. E. (1995). Bayes factor. Journal of the American Statistical Association, 90(430), 773-795.

Lacourse, E., Côté, S., Nagin, D. S., Vitaro, F., Brendgen, M., \& Tremblay, R. E. (2002). A longitudinal-experimental approach to testing theories of antisocial behaviour development. Development and Psychopathology, 14, 909-924.

Lacourse, E., Nagin, D., Tremblay, R. E., Vitaro, F., \& Claes, M. (2003). Developmental trajectories of boys' delinquent group membership and facilitation of violent behaviours during adolescence. Development and Psychopathology, 15, 183-197.

Lerner, R. M. (1996). Relative plasticity, integration, temporality, and diversity in human development: A developmental contextual perspective about theory, process, and method. Developmental Psychology, 32(4), 781-786.

Loeber, R., \& Farrington, D. P. (1998). Serious and violent juvenile offenders: Risk factors and successful interventions. Thousand Oaks, CA: Sage.

Maldonado-Molina, M., Piquero, A. R., Jennings, W., Bird, H., \& Canino, G. (2009). Trajectories of delinquency among Puerto Rican children and adolescents at two sites. Journal of Research in Crime and Delinquency, 46(2), 144-181.

Maldonado-Molina, M., Reingle, J., Tobler, A., Jennings, W., \& Komro, K. (2010). Trajectories of physical aggression among Hispanic urban adolescents and young adults: An application of latent trajectory modeling from ages 12 to 18. American Journal of Criminal Justice, 35(3), 121-133.

Marti, N., Stice, E., \& Springer, D. W. (2010). Substance use and abuse trajectories across adolescence: A latent trajectory analysis of a community-recruited sample of girls. Journal of Adolescence, 33(3), 449-461.

Masse, L. N., \& Barnett, W. S. (2002). A benefit cost analysis of the Abecedarian Early Childhood Intervention. New Brunswick, NJ: National Institute for Early Education Research.

Moffitt, T. E. (2001). Childhood predictors differentiate life-course persistent and adolescencelimited antisocial pathways among males and females. Development and Psychopathology, 13(2), 355-375.

Moffitt, T. E., Caspi, A., Rutter, M., \& Silva, P. A. (2001). Sex differences in antisocial behaviour: Conduct disorder, delinquency, and violence in the Dunedin Longitudinal Study. Cambridge, UK: Cambridge University Press. 
International Journal of Child, Youth and Family Studies (2011) 2.1: 263-293

Mrazek, P. J., \& Brown, C. H. (2002). An evidence-based literature review regarding outcomes in psychosocial prevention and early prevention in young children. In C. C. Russell (Ed.), The state of knowledge about prevention/early intervention (pp. 42-144). Toronto, ON: Invest in Kids Foundation. Available at: http://www.investinkids.ca/parents/about-us/ourresearch/articletype/articleview/articleid/1230/review-of-preventionearly-interventionresearch.aspx

Nagin, D. S. (1999). Analyzing developmental trajectories: A semi-parametric, group-based approach. Psychological Methods, 4(2), 139-157.

Nagin, D. S. (2005). Group-based modeling of development. Cambridge, MA: Harvard University Press.

National Council on Welfare. (2004). Welfare incomes 2003. Retrieved January 25, 2008, from http://www.ncwcnbes.net/documents/researchpublications/ResearchProjects/WelfareIncomes /2003Report_Spring2004/ReportENG.pdf

Nores, M., Belfield, C. R., Barnett, W. S., \& Schweinhart, L. (2005). Updating the economic impacts of the High/Scope Perry Preschool Program. Educational Evaluation and Policy Analysis, 27(3), 245-261.

Odgers, C. L., Moffitt, T. E., Broadbent, J. M., Dickson, N., Hancox, R. J., Harrington, H., et al. (2008). Female and male antisocial trajectories: From childhood origins to adult outcomes. Development and Psychopathology, 20(2), 673-716.

Ontario Ministry of Community and Social Services. (2003). Ontario disability support program. Retrieved January 25, 2008, from http://www.mcss.gov.on.ca/mcss/english/pillars/social/ odsp-isdirectives/ODSP_incomesupport.htm

Peters, R., Bradshaw, A. J., Petrunka, K., Nelson, G., Herry, Y., Craig, W. M., et al. (2010). The Better Beginnings, Better Futures Project: An ecological, community-based prevention approach: Findings from Grade 3 to Grade 9. Monograph for the Society for Research in Child Development, 75, 1-176.

Postlethwait, A. W., Barth, R. P., \& Guo, S. (2010). Gender variation in delinquent behavior changes of child welfare-involved youth. Children and Youth Services Review, 32(3), 318-324.

Reynolds, A. J., Temple, J. A., Robertson, D. L., \& Mann, E. A. (2002). Age 21 cost-benefit analysis of the Title I Chicago child-parent centers. Educational Evaluation and Policy Analysis, 24(4), 267-303.

Rutter, M. (1986). Child psychiatry: The interface between clinical and developmental research. Psychological Medicine, 16(1), 151-169.

Savoie, J. (2006). Youth self-reported delinquency. Statistics Canada Catalogue no. 85-002-XPE. Juristat, 27(6). Ottawa: Statistics Canada.

Schonberg, M. A., \& Shaw, D. S. (2007). Risk factors for boy’s conduct problems in poor and lowermiddle-class neighborhoods. Journal of Abnormal Child Psychology, 35(5), 759-772.

Canadian Research Perspectives for Youth at Risk for Serious and

Violent Offending: Implications for Crime Prevention Policies and Practices 
International Journal of Child, Youth and Family Studies (2011) 2.1: 263-293

Serbin, L. A., Stack, D. M., De Genna, N., Grunzeweig, N., Temcheff, C. E., Schwartzman, A. E., et al. (2004). When aggressive girls become mothers: Problems in parenting, health, and development across two generations. In M. Putallaz \& K. Bierman (Eds.), Aggression, antisocial behavior, and violence among girls: Duke series in child development and public policy (pp. 262-285). New York: Guilford Press.

Silverthorn, P., \& Frick, P. J. (1999). Developmental pathways to antisocial behavior: The delayedonset pathway in girls. Development and Psychopathology, 11(1), 101-126.

Statistics Canada. (1995). National longitudinal survey of children and youth: Overview of survey instruments from 1994-95 data collection cycle I. Statistics Canada Catalogue no. 89F0077XIE. Ottawa, ON: Statistics Canada. Retrieved December 4, 2008, from: http://www.statcan.gc.ca/pub/89f0077x/89f0077x1996001-eng.pdf

Tremblay, R. E., Van Aken, M. A. G., \& Koops, W. (Eds.). (2009). Development and prevention of behaviour problems: From genes to social policy. New York: Psychology Press.

Waddell, C., Hua, J. M., Garland, O. M., Peters, R. D., \& McEwan, K. (2007). Preventing mental disorders in children: A systematic review to inform policy-making. Canadian Journal of Public Health, 98(3), 166-173.

Welsh, B., (2007). Evidence-based crime prevention: Scientific basis, trends, results and implications for Canada. Research Report, National Crime Prevention Centre. Ottawa, ON: Public Safety Canada.

Wiesner, M., \& Windle, M. (2006). Young adult substance use and depression as a consequence of delinquency trajectories during middle adolescence. Journal of Research on Adolescence, 16(2), 239-264.

Canadian Research Perspectives for Youth at Risk for Serious and 